\title{
OCORRÊNCIAS DE INCÊNDIOS FLORESTAIS NO PARQUE NACIONAL DE ILHA GRANDE - BRASIL
}

\author{
Letícia de Paulo Koproski ${ }^{1}$ \\ Antonio Carlos Batista ${ }^{2}$ \\ Ronaldo Viana Soares ${ }^{3}$
}

\begin{abstract}
RESUMO
O fogo é um agente com vasta capacidade de alteração do ambiente e por isso representa uma grande ameaça às Unidades de Conservação em todo o País. Nos últimos cinco anos ocorreram cinqüenta e dois incêndios no Parque Nacional de Ilha Grande - PNIG. Os incêndios no PNIG têm se verificado com uma média de dez ocorrências por ano, com uma área queimada média anual de $24.971,1$ hectares. Nesse período $92 \%$ das causas foram de natureza humana. Esses dados revelam a fragilidade do Parque Nacional de Ilha Grande frente aos incêndios florestais e são suficientes para alertar sobre a importância do problema do fogo em Unidades de Conservação, e a necessidade da elaboração de Planos de Prevenção e Combate a Incêndios em ambientes naturais.
\end{abstract}

Palavras chave: Fogo, Unidades de Conservação, Incêndios no Brasil, Proteção florestal, rio Paraná.

\section{THE OCCURRENCES OF FOREST FIRES IN THE ILHA GRANDE NATIONAL PARK, BRAZIL}

\begin{abstract}
Fire is a huge threat to Brazilian Units Conservation, because it is an agent with a wide capacity to modificate the environment. In the five year-old period analised, fifty-two forest fires happened in Ilha Grande National Park -IGNP. A medium of 10.4 occurrences per year was observed and 24,971.1 ha were burned in medium per year. In this period, $92 \%$ of the forest fires were caused by humans. These data bring out the fragility of IGNP face to forest fires and are sufficient to alert about the importance of fire problem and the need of Forest Fires Control Plans in Brazilian Conservation Units.

Key-words: Fire behavior, Conservation Units, Brazilian fires, Forest protection, Paraná river
\end{abstract}

\section{INTRODUÇÃO}

Os incêndios florestais são uma ameaça constante à integridade das unidades de conservação. podem gerar inúmeros danos e, em certas ocasiões, perdas irreparáveis à flora e à fauna. o fogo pode afetar vários componentes do ambiente, como o solo, a vegetação, a fauna e o ar atmosférico; e sob alguns desses componentes seus efeitos ainda geram controvérsias. os prejuízos podem ser incalculáveis do ponto de vista científico, conservacionista e financeiro (Oliveira, Batista e Milano, 2000).

Anualmente o fogo destrói imensas áreas naturais em todo o mundo. no Brasil os incêndios em ecossistemas naturais causam sérias preocupações aos setores ligados ao ambiente. a inexistência de políticas adequadas de prevenção e combate aos incêndios tem levado a perdas ambientais elevadas em todo o país. Considerando que a maioria das causas dos incêndios em ambientes naturais é decorrente de ações humanas, são necessárias medidas de prevenção, controle e supressão de incêndios, para garantir a conservação dos recursos naturais.

A proteção das Unidades de Conservação contra o fogo torna-se mais eficiente e criteriosa quando existe um plano prévio das atitudes a serem tomadas no caso da ocorrência de incêndios. Os planos de prevenção e combate a incêndios florestais possuem três objetivos básicos de defesa, que são: prevenir tanto quanto possível o início dos incêndios; controlar os incêndios que não puderam ser prevenidos enquanto ainda pequenos e minimizar o tamanho e os danos dos incêndios ocorridos (Soares e Batista, 1998).

\footnotetext{
${ }^{1}$ leticia@floresta.ufpr.br, Médica Veterinária, Programa de Pós-Graduação em Ciências Florestais, UFPR; Pesquisadora Projeto Fogo, Associação Mata Ciliar, av. Sete de setembro, 4079/11, Batel, Curitiba, Paraná, 80250-210

${ }^{2}$ batista@floresta.ufpr.br, Prof. Dr., Departamento de Engenharia Florestal, UFPR

3rvsoares@floresta.ufpr.br, Prof. Dr., Departamento de Engenharia Florestal, UFPR
} 
Informações e estatísticas sobre ocorrências anteriores de fogo e aspectos gerais de uma determinada área são necessárias para o planejamento e elaboração de um plano de prevenção e combate a incêndios. Esses dados são essenciais para o direcionamento das ações e futuras avaliações do plano no sentido de se estabelecer com mais eficiência os métodos e os objetivos da prevenção e do combate (Soares e Batista, 1998; Ribeiro, Lima e Siqueira, 2002).

Dessa forma, o presente trabalho visa analisar as informações sobre os incêndios ocorridos no Parque Nacional de Ilha Grande no período entre 1999-2003, com o objetivo de levantar subsídios para a implementação de ações de prevenção e combate a incêndios nessa Unidade de Conservação.

\section{MATERIAL E MÉTODOS}

O Parque Nacional de Ilha Grande (PNIG) é uma Unidade de Conservação de proteção integral situada na divisa dos Estados do Paraná e Mato Grosso do Sul. Foi criado em 30 de setembro de 1997 e está localizado na região sul da planície de inundação do alto rio Paraná, entre as coordenadas $23^{\circ} 15^{\prime}$ a $24^{\circ} 05^{\prime} \mathrm{S}$ e $53^{\circ} 40^{\prime}$ a $54^{\circ} 17^{\prime} \mathrm{W}$. Abrange os municípios de Guaíra, Altônia, São Jorge do Patrocínio, Vila Alta e Icaraíma no Paraná e Mundo Novo, Eldorado, Naviraí e Itaquiraí no Mato Grosso do Sul. É formado por um arquipélago fluvial com centenas de ilhas, muitas delas de curta existência, das quais as maiores são as Ilhas Grande, Bandeirantes e Peruzzi; além de uma estreita e longa faixa de várzea situada na margem esquerda do rio Paraná. Possui área total de 78.875 hectares.

A região é caracterizada pelo clima subtropical úmido mesotérmico (Cfa), com verões quentes e geadas pouco freqüentes, com tendência de concentração de chuvas nos meses de verão, sem estação seca definida, sendo que o período mais seco normalmente ocorre de maio a setembro. A média das temperaturas dos meses mais quentes é superior a $22^{\circ} \mathrm{C}$ e a dos meses mais frios inferior a $18^{\circ} \mathrm{C}$ (Campos, 2001).

A formação florestal do PNIG é classificada como floresta estacional semidecidual. Duas tipologias florestais caracterizam a área, sendo possível identificar a Floresta Estacional Semidecidual Submontana e a Floresta Estacional Semidecidual Aluvial (Campos e Souza, 1997; ELETROSUL, 1986; IBGE, 1992).

Devido a sua recente criação, o PNIG ainda enfrenta muitos problemas na sua manutenção. Sofre as conseqüências de inúmeros impactos ambientais, que são agravados e facilitados pelo fato do Parque ser formado por inúmeras ilhas cercadas por rios facilmente navegáveis. O PNIG é cercado por propriedades que em sua maioria desenvolvem atividades agropecuárias. Além dos impactos sofridos no entorno, conta ainda como a presença de ribeirinhos nas diversas ilhas, que desenvolvem como forma de sobrevivência atividades relacionadas com a agropecuária, pesca e apicultura. O fogo é comumente utilizado no manejo dessas atividades na região.

Os relatórios e registros de ocorrências de incêndios florestais - ROIs, compreendidos entre os anos de 1999-2003, obtidos da base de dados da Sede do Parque Nacional de Ilha Grande (IBAMA), foram analisados para a definição das seguintes variáveis: número de ocorrências de incêndios no período e por ano; extensão da área queimada no período e por ano; distribuição anual dos incêndios; causas das ocorrências. Esses dados foram coletados para a realização do presente trabalho $\mathrm{e}$ também para a elaboração do Plano de Manejo dessa Unidade de Conservação.

\section{RESULTADOS E DISCUSSÃO}

No período compreendido entre 19992003, ocorreram cinqüenta e dois incêndios no Parque Nacional de Ilha Grande, com uma média de 10,4 ocorrências por ano. Em 1999 aconteceram vinte incêndios, em 2000 cinco, em 2001 quatro, em 2002 dezessete e em 2003 seis. O número total de incêndios ocorridos é elevado e contrapõe-se ao objetivo de uma Unidade de Conservação: a proteção dos recursos naturais.

A área queimada no período totalizou 124.854,5 hectares, o que representa uma média anual de 24.970,9ha. Considerando a área total do Parque, que é de $78.875 \mathrm{ha}$, significa que o PNIG teria queimado 1,5 vezes em cinco anos, caso os incêndios fossem igualmente distribuídos em toda a sua 
extensão. No entanto, sabe-se que algumas regiões queimaram mais do que outras.

As áreas atingidas pelo fogo apresentaram uma grande variação durante os anos de 1999 até 2003. Estima-se, pela avaliação dos registros dos incêndios que, em 1999 cerca de 52.417,5ha tenham sido atingidos, em 2000 aproximadamente 5.035ha, em 2001 cerca de 3.500 ha, em 2002 por volta de 27.000 ha e em 2003 aproximadamente 36.902 hectares. O número de incêndios não está diretamente relacionado com a extensão da área queimada. Observou-se, que em 2002 dezessete incêndios atingiram $27.000 \mathrm{ha}$ e em 2003 seis incêndios atingiram uma área aproximada de 37.000ha.

Existem registros das épocas de ocorrência de trinta e cinco incêndios observados no PNIG (Figura 1). De acordo com esses dados, observa-se que os meses críticos para a ocorrência de incêndios foram: agosto, com quinze ocorrências e setembro, com seis. Embora o número de incêndios registrados não corresponda ao total de ocorrências do período analisado, pode-se verificar uma certa tendência para a caracterização da estação normal de perigo de incêndios, já que $60 \%$ dos incêndios ocorreram no período entre agosto e setembro.

Foram analisadas as causas de vinte e seis incêndios entre 1999-2003 (Figura 2). As categorias das causas foram definidas de acordo com a classificação utilizada pelo IBAMA nos registros de ocorrências de incêndios. As causas de $92,3 \%$ dos incêndios foram de natureza humana. É importante observar que o grupo mais significativo, em função da freqüência, foi "criminoso", com $34 \%$ das ocorrências e em $19 \%$ dos registros a causa foi desconhecida. Esses dados evidenciam o uso do fogo em diversas atividades ilegais na região. Sendo assim, é necessário implementar um programa de educação ambiental que vise conscientizar a população sobre a importância da conservação do Parque Nacional de Ilha Grande e divulgue a legislação pertinente.

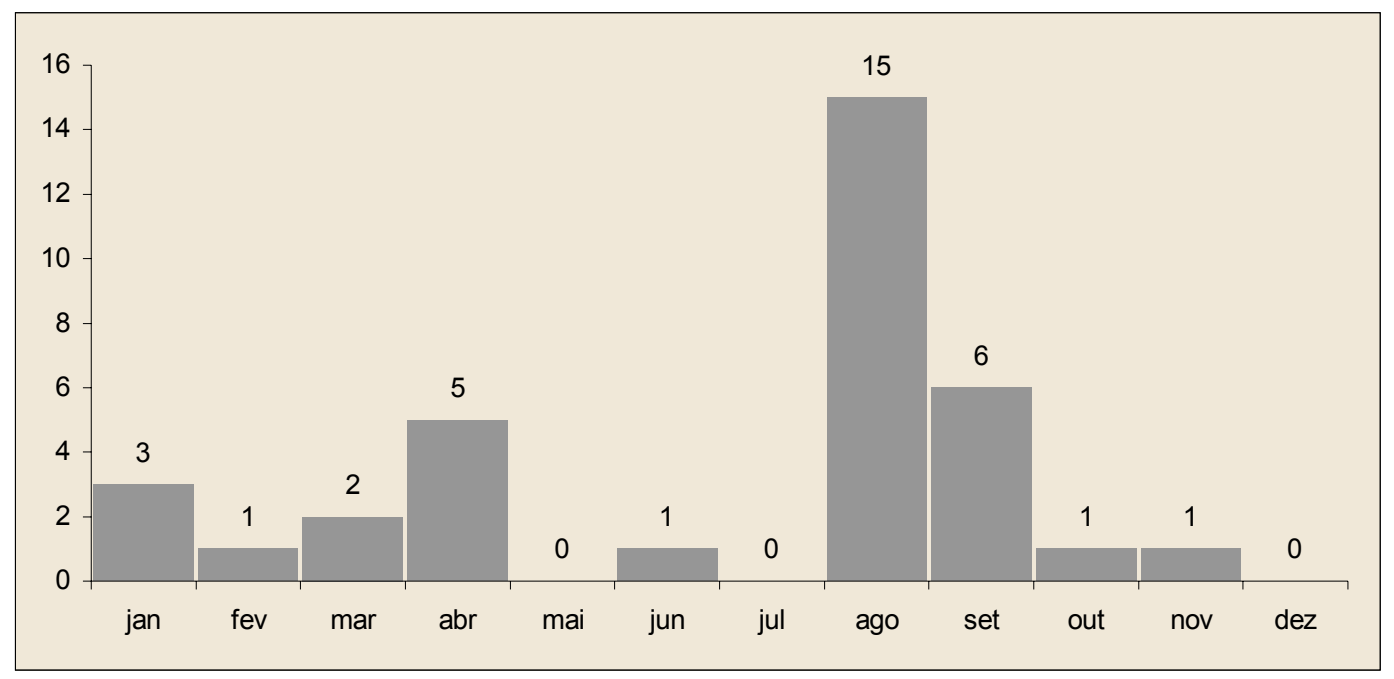

Figura 1: Distribuição das ocorrências dos incêndios no PNIG - 1999/2003

Figure 1: Fire occurences distribuition in IGNP - 1999/2003 


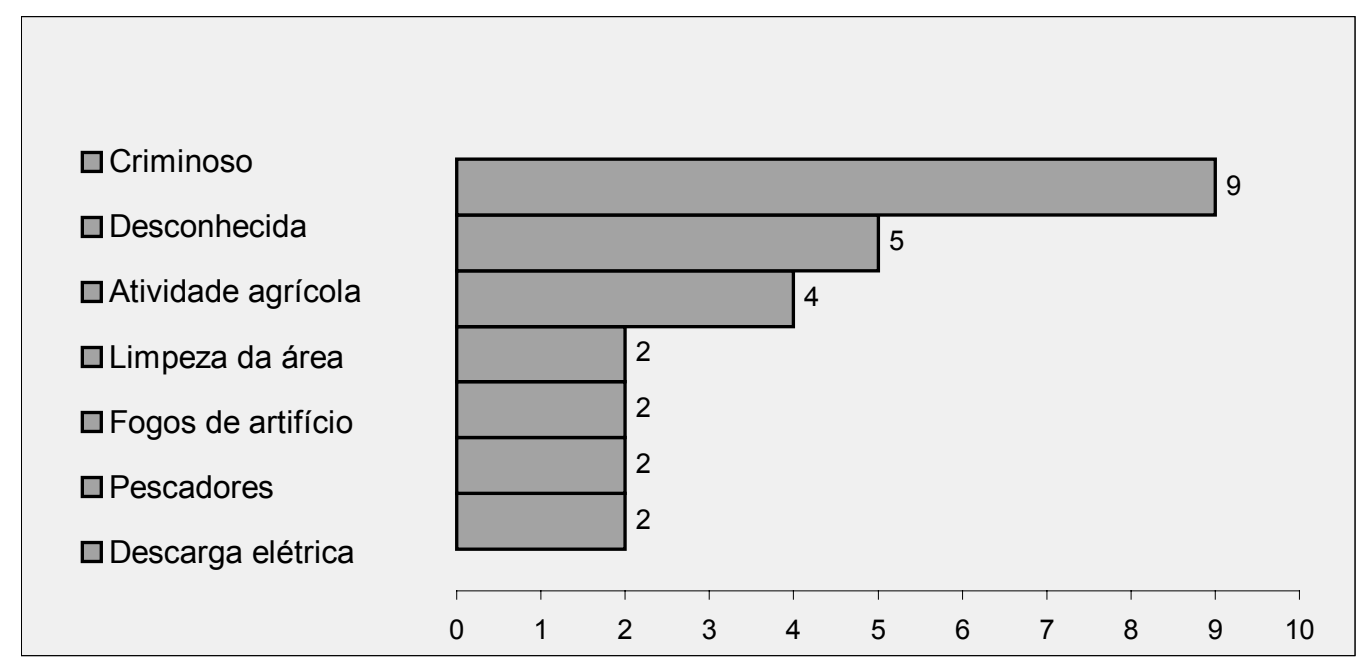

Figura 2: Causas dos incêndios florestais no PNIG - 1999/2003

Figure 2 Causes of forest fires in IGNP - 1999/2003

\section{CONCLUSÃO}

Pelos registros de incêndios encontrados na base de dados do IBAMA observa-se que os incêndios no PNIG têm se verificado com uma média de 10,4 ocorrências por ano, com uma área queimada média total anual de 24.970,9 hectares.

Esses dados revelam a fragilidade do Parque Nacional de Ilha Grande frente aos incêndios florestais, devido primeiramente às atividades desenvolvidas tanto no entorno, como na própria Unidade, tais como: caça, pesca, queima de pastagens, exploração de produtos florestais e apicultura, que são fontes importantes de ignição; e também devido às características de inflamabilidade da vegetação do Parque e às condições meteorológicas, que potencializam essa característica da vegetação.

Essas considerações são baseadas nos poucos dados obtidos que, no entanto, são suficientes para alertar sobre a problemática do fogo na área do PNIG e a necessidade de se traçar um plano para o estabelecimento das diretrizes e ou seu redirecionamento com o intuito de reduzir ao máximo o número de ocorrências de incêndios e a extensão da área queimada nessa Unidade de Conservação.

\section{AGRADECIMENTOS}

Ao IBAMA e a equipe do Parque Nacional de Ilha Grande, em especial a Maude Nancy Joslin Motta, pelos conselhos e pela dedicação por fornecer as informações, e a
Paulo Roberto Machado pelo apoio ao projeto. Ao Instituto Mater Natura, executor do Plano de Manejo dessa Unidade de Conservação, em especial a Augusto César Svolenski e a Karina Oliveira. A Associação Mata Ciliar pela confiança e apoio ao projeto fogo, sem a qual não seria possível a realização desse trabalho. A Coordenação de Aperfeiçoamento de Pessoal de Nível Superior (CAPES) pela bolsa concedida.

\section{REFERÊNCIAS}

CAMPOS, J. B. Parque Nacional de Ilha Grande re-conquista e desafios. $2^{\text {a }}$ ed. IAP/CORIPA Maringá, 2001, 118p.

CAMPOS, J. B.; SOUZA, M. C. A vegetação. In: VAZZOLER, A. E. A. de M.; AGOSTINHO, A. A.; HAHN, N. S. (Eds). A planície de inundação do alto rio Paraná: Aspectos físicos, biológicos e socioeconômicos. Maringá. EDUEM: 1997. p.333-334.

ELETROSUL - CENTRAIS ELÉTRICAS DO SUL DO BRASIL. Ilha Grande - A vegetação da área de influência do reservatório da usina hidrelétrica de Ilha Grande (PR/MS). Florianópolis, 1986. 52p.

IBGE - INSTITUTO BRASILEIRO DE GEOGRAFIA E ESTATÍSTICA, IBGE. Manual técnico da vegetação brasileira. Rio de Janeiro, 1992. 92p. (Séries Manuais Técnicos em Geociências;1). 
OLIVEIRA, D. dos S. de.; BATISTA, A. C.; MILANO, M. S. FOGO EM UNIDADES DE CONSERVAÇÃO. In: Congresso Brasileiro de Unidades de Conservação, 2, 2000, Campo Grande. Anais do II Congresso Brasileiro de Unidades de Conservação - Vol II Trabalhos Técnicos. Campo Grande, 2000. p. 200-207.

RIBEIRO, G. A.; LIMA, G. S.; SIQUEIRA, L. de. O PARQUE NACIONAL DA SERRA DA CANASTRA E A OCORRÊNCIA DE INCÊNDIOS FLORESTAIS. In: Congresso Brasileiro de Unidades de Conservação, 3, 2002, Fortaleza. Anais do III Congresso Brasileiro de Unidades de Conservação Trabalhos Técnicos. Fortaleza, 2002. p. 473479.

SOARES, R. V. e BATISTA, A. C. Prevenção dos incêndios Florestais. Curso de especialização por tutoria à distância - Módulo 5. Associação Brasileira de Educação Agrícola Superior, 1998. 33p. 